\title{
Under nutrition as a predictor of poor academic performance; the case of Nekemte primary schools students, Western Ethiopia
}

Dejene Seyoum ${ }^{1}$, Reta Tsegaye ${ }^{1 *}$ (D) and Amanuel Tesfaye ${ }^{2}$

\begin{abstract}
Objective: Though gradual improvements are exist; Ethiopia's learning outcomes are still low in primary schools. Academic achievement of school age children can be affected by several factors such as nutritional status, socioeconomic and demographic factors. The aim of this study was to assess predictors of poor academic performance in Nekemte Primary school students, Western Ethiopia.

Results: A total of 362 schoolchildren and their parents were involved in the study. The study involved interviewing the participants and their parents, anthropometric measurement of participants and their document review. The prevalence of stunting and underweight was $30.2 \%$ and $45.9 \%$ respectively. Of the total study participants, 32.2\% of them were poor in academic achievement. Variables like Being underweight (Adjusted odds ratio (AOR): 0.57; 95\% Confidence interval (CI) 0.23-0.82), Skipping breakfast (AOR: 2.1; 95\% Cl 1.42-5.76), stunting (AOR: 0.66; $95 \% \mathrm{Cl}$ 0.12-0.93), being male (AOR: $2.8 ; 95 \%$ Cl 1.79-4.52), participants whom mothers didn't attend formal education (AOR: $0.62 ; 95 \% \mathrm{Cl} 0.37-0.92$ ) were significantly associated with academic performance. Thus, Modifiable factors like under nutrition should be a great concern to improve the overall achievement of children in schooling.
\end{abstract}

Keywords: Under nutrition, Academic performance, Nekemte, Western Ethiopia

\section{Introduction}

Education is a key factor for development and can also be a burden for a country if there is high failure rate, since it consumes much resource from a country. Besides, all parents want their children to be smart and intellectual; therefore school failure is stress full for both parents and students. Children are considered the greatest national resource of any country who build the future of the nation, and schooling is an instrument of individual and social change, increasing the probabilities of general wellbeing $[1,2]$.

Though gradual improvements are exist, Ethiopia's learning outcomes are still low in primary schools. For instance, over a half of 4th grade and 8th grade students tested in 2015 scored below proficiency level defined as "Below Basic" in all subjects, except English for grade 8.

\footnotetext{
*Correspondence: retatg@gmail.com

${ }^{1}$ Institute of Health Sciences, Wollega University, Nekemte, Ethiopia

Full list of author information is available at the end of the article
}

This means that the student has minimal understanding of the subject and lacks the skills to solve simple problems appropriate for that grade level [3]. Academic achievement of school age children can be affected by several factors such as nutritional status, demographics, and socio-economic factors [4].

Several studies have shown that malnutrition negatively affects the academic performance of students [5-10]. The consequences of malnutrition should be a significant concern for policymakers in Ethiopia, where about 5.8 million children under 5 years (38\%) are suffering from chronic malnutrition (stunting or low heightfor-age), according to the most recent Demographic and Health Survey (DHS) [11]. A cross sectional survey conducted in southern Ethiopia revealed that the prevalence of stunting was $16.9 \%$ and its correlation with school underperformance was significantly high [12]. Similarly studies conducted in Goba town and primary schools of Hawa Galan district shown that nutritional status like stunting, underweight and wealth index were found to be 
correlated with academic performance of students $[4,13]$. On the other hand, there are some studies which revealed that there was no significant association between academic performance and nutritional status $[1,14]$.

Despite the existence of studies conducted on prevalence of under nutrition and its correlation with academic performance in Ethiopia, it is still limited to certain settings and varying associations between under nutrition and academic performance. In the current study area, there is no previous published study on academic performance of primary schools and its association with nutritional status. Therefore, this study was aimed to assess factors associated with poor academic performance in Nekemte Primary school students, Western Ethiopia.

\section{Main text \\ Methods \\ Study design, period and setting}

An institution based cross-sectional study was conducted from April to May, 2016 in Nekemte full cycle primary schools. Nekemte is an administrative capital of the East Wollega Zone located $328 \mathrm{~km}$ to the West of Addis Ababa, the capital city of Ethiopia. It has a latitude and longitude of $9^{\circ} 5^{\prime} \mathrm{N} 36^{\circ} 33^{\prime} \mathrm{E} / 9.083^{\circ} \mathrm{N} 36.550^{\circ} \mathrm{E}$ and elevation of $2088 \mathrm{~m}$. According to the 2007 national census, it has a population of 75,219 ( 38,385 males, 36,834 females) [15].

\section{Population and sampling}

A stratified sampling technique was employed to select the study units from the schools. First the selected full cycle primary school students were stratified based on their grades. Then proportional allocation was made for each grade. Study units were selected by using simple random sampling. Students list were obtained from the schools and used as a sampling frame. The sample size was determined by using single population proportion formula, $\boldsymbol{n}=\mathrm{Z} \alpha / 2^{2}(p q) / d^{2}$ taking prevalence of stunting (38\%) from national nutrition strategy 2010 to calculate for $\mathrm{P}$ giving any particular outcome to be within $5 \%$ marginal error and $95 \% \mathrm{CI}$ of certainty $(\alpha=05)$. Based on this Assumption the actual sample size for study was 362 .

Data collection Data were collected by interview administered questionnaires for both parents and children jointly while accompanying their children to school. Socio demographic variables of children and parents were collected from the parents themselves. The data were collected by four nursing diploma holders and data quality was insured by training them and strict supervision during data collection. Pre testing on $10 \%$ of the sample size was conducted prior to the main data collection at another school different from the sampled schools. Docu- ment review was also done by principal investigator to identify students' average grade report of academic year 2015-2016. Academic performance was assessed by adding all subjects given in two consecutive semesters of the academic year and the average score of each student was computed. The data collection procedure also included anthropometric measurement of school children measured in separate class at their school. Weight of students was measured using beam balance with light closing, and height of students was measured to the nearest $1 \mathrm{~cm}$ on standing position without shoes and frequent calibrating of the scale was done. All measurements were taken twice and the mean value was used for data analysis.

\section{Measurement of academic achievements}

All subjects that the students were given in the academic year 2015/16 were considered to determine the academic performance of the students. Average score was calculated by taking the result of two consecutive semesters of the above-mentioned year. To examine the effect of nutritional status on educational performance, their annual average were divided into two categories; poor score and good score based on the mean value of their annual average.

\section{Data management and statistical analysis}

Sex, age, height and weight transferred to WHO Anthro plus software to convert nutritional data into Z-scores of the indices. To determine nutritional status of the children, the age and sex-specific growth charts were used. Height for age Z-scores (HAZ) below -2 SD of the reference population indicates stunting. Weight for height Z-scores (WHZ) below -2 SD of the reference population indicates wasting. Weight for age Z-scores (WAZ) below $-2 \mathrm{SD}$ of the reference population is underweight [16]. Data were checked for completeness, coded and entered into SPSS version 21.0 software for analysis. Frequency tables, proportions and summarizing using texts were used to present study results. Analysis was done by using univariate and multivariable logistic regression model. Variables with a P-value less or equal to 0.2 in the univariate analysis were included in the multivariable logistic regression model. Finally, significant associations between good academic performance and independent variables with $95 \%$ confidence interval were determined at P-value less than 0.05 .

\section{Study variables}

The dependent variable in this study was academic performance (average grade score of students) as poor and good academic performance Those whose annual grade average below the mean were regarded as poor and those whose annual grade average above the mean were termed 
as good academic performers. The independent variables for this study include age, sex, educational level of parents, occupation of parents, participants' nutritional status variables like underweight, stunting and wasting.

\section{Results}

Socio-demographic characteristics of the respondents and parents

A total of 362 students were enrolled into this study. One hundred sixty-nine (46.6\%) of them were males and 193 (53.2\%) females. The mean (SD) ages of respondents were $12.9( \pm 2.2)$ years. Majority $(80.2 \%)$ were in the age range of $10-14$ and Oromo in ethnicity (84.8\%). Three hundred twenty-nine, 329 (90.6\%) of the participants live in urban kebeles of Nekemte town. The majority of their fathers $(81 \%)$ were at least able to read and write while only $17.4 \%$ of their mothers were able to read and write. More than three-fifth of parents were either government or private employee and 59\% of families of the study participants live in their own house (Table 1).

\section{Nutritional status}

Anthropometric assessment Based on WHO reference standards, the prevalence of underweight was $45.9 \%$. Students' height for age was also calculated. Accordingly; those students with height for age below reference standard was $30.2 \%$.

\section{Academic performance}

The mean score for the study participants was 64.37 with standard deviation of 9.63 . Of the total study participants, 117 (32.2\%) of them scored below the mean value and the $67.8 \%$ of them scored above the mean value. Being underweight was one of the anthropometric measurement affected the students' academic performance (AOR: 0.57; 95\% CI 0.23-0.82). Skipping breakfast (AOR: $2.1 ; 95 \%$ CI 1.42-5.76) was also associated negatively with the academic outcome of the student. Children who were stunted (AOR: 0.66; 95\% CI 0.12-0.93) and underweight (AOR: 0.57; 95\% CI 0.23-0.82) were less likely to have good academic performance. Participants' and parents' socio-demographic variables were also predictors of poor academic performance of these school children. Male participants were 2.8 times more likely to be good academic performers (AOR: 2.8; 95\% CI 1.79-4.52). Those participants whom mothers didn't attend formal education (AOR: 0.62; 95\% CI 0.37-0.92) were less likely to be a good academic performer compared to their counterparts (Table 2). Residence, workload, occupation of family and child wasting were not associated with school performance in this study.
Table 1 Socio-demographic variables of respondents and their parents in Nekemte primary schools, Western Ethiopia, $2016(\mathrm{~N}=362)$

\begin{tabular}{|c|c|c|}
\hline Variables & Frequency & Percent \\
\hline \multicolumn{3}{|l|}{ Grade } \\
\hline Five & 102 & 28.1 \\
\hline Six & 88 & 24.2 \\
\hline Seven & 91 & 25.1 \\
\hline Eight & 81 & 22.3 \\
\hline \multicolumn{3}{|l|}{ Sex } \\
\hline Male & 169 & 46.6 \\
\hline Female & 193 & 53.2 \\
\hline \multicolumn{3}{|l|}{ Age group } \\
\hline $10-14$ & 291 & 80.2 \\
\hline $15-19$ & 71 & 19.6 \\
\hline \multicolumn{3}{|l|}{ Residence } \\
\hline Urban & 329 & 90.6 \\
\hline Rural & 33 & 9.1 \\
\hline \multicolumn{3}{|l|}{ Religion } \\
\hline Orthodox & 150 & 41.3 \\
\hline Muslim & 48 & 13.3 \\
\hline Protestant & 117 & 32.2 \\
\hline Other & 47 & 12.9 \\
\hline \multicolumn{3}{|l|}{ Ethnicity } \\
\hline Oromo & 308 & 85.01 \\
\hline Amhara & 37 & 10.2 \\
\hline Others $^{a}$ & 17 & 4.7 \\
\hline \multicolumn{3}{|c|}{ Number of people living in the house } \\
\hline 2 to 4 & 108 & 29.8 \\
\hline 5 to 12 & 254 & 70.2 \\
\hline \multicolumn{3}{|l|}{ Mothers educational status } \\
\hline Unable to read and write & 79 & 21.8 \\
\hline Read and write & 63 & 17.4 \\
\hline Completed primary & 67 & 18.5 \\
\hline Completed secondary & 24 & 6.6 \\
\hline College and above & 129 & 35.5 \\
\hline \multicolumn{3}{|l|}{ Fathers educational status } \\
\hline Unable to read and write & 69 & 19 \\
\hline Read and write & 88 & 24.2 \\
\hline Completed primary & 14 & 3.9 \\
\hline Completed secondary & 127 & 35 \\
\hline College and above & 64 & 17.6 \\
\hline \multicolumn{3}{|l|}{ Mothers occupation } \\
\hline House wife & 121 & 33.3 \\
\hline Farmer & 17 & 4.7 \\
\hline Merchant & 78 & 2.1 \\
\hline Government employee & 79 & 21.8 \\
\hline Private employee/NGO & 36 & 9.9 \\
\hline Daily laborer & 31 & 8.5 \\
\hline \multicolumn{3}{|l|}{ Fathers occupation } \\
\hline Farmer & 10 & 2.8 \\
\hline Merchant & 108 & 29.8 \\
\hline
\end{tabular}


Table 1 (continued)

\begin{tabular}{lcl}
\hline Variables & Frequency & Percent \\
\hline Government employee & 73 & 20.1 \\
Private employee/NGO & 150 & 41.3 \\
Daily laborer & 21 & 5.8 \\
House ownership & & \\
Private & 214 & 59 \\
Rent & 148 & 41 \\
Number of rooms in the house & & \\
1 to 3 & 161 & 44.1 \\
4 and above & 201 & 55.5 \\
Latrine & & \\
Yes & 350 & 96.4 \\
No & 12 & 3.3 \\
\hline
\end{tabular}

a Guraghe, Tigre

\section{Discussion}

The goal of this study was to assess the nutritional status and associated factors affecting academic performance of children in primary schools of Nekemte, Ethiopia. The prevalence of stunting and underweight in the study area was $30.2 \%$ and $45.7 \%$ respectively. This study is similar with study conducted in Nuwara Eliya Educational Zone, India and Northern Ethiopia [1, 17] but lower than study conducted by Dawud et al. and the national estimate of $38 \%[11,18]$. This difference may attribute to difference in geographical setting and study period and socioeconomic level.

In the present study, stunted children had lower academic score than those non-stunted. Under weight is also another predictor of poor academic performance. Similar study conducted in Canadian school aged children, India, and Bale Goba revealed that stunted children were poor academic performers $[1,4,5]$. In this study, underweight children were $43 \%$ less in academic performance than those who were normal weight. However study conducted in Northern Ethiopia shown that there was no significant difference in academic performance based on weight for age of participants [14]. This may be attributed to non-storage of nutrients in different forms

Table 2 Factors associated with academic performance at primary schools of Nekemte Town, Western Ethiopia, 2016 $(\mathrm{N}=362)$

\begin{tabular}{|c|c|c|c|c|c|}
\hline \multirow[t]{2}{*}{ Variables } & \multicolumn{2}{|c|}{ Academic performance } & \multirow[t]{2}{*}{ Univariate OR (95\% Cl) } & \multirow[t]{2}{*}{ Multivariable OR $(95 \% \mathrm{Cl})$} & \multirow[t]{2}{*}{ P-value } \\
\hline & Good & Poor & & & \\
\hline \multicolumn{6}{|l|}{ Sex } \\
\hline Male & $113(31.2)$ & $56(15.5)$ & $2.85(1.82,4.62)$ & $2.8(1.79,4.52)^{*}$ & 0.0001 \\
\hline Female & $80(22.1)$ & $113(31.2)$ & 1.00 & 1.00 & \\
\hline \multicolumn{6}{|l|}{ Residence } \\
\hline Urban & $265(73.2)$ & $64(17.7)$ & $3(1.15,8.11)$ & $1.84(0.83-2.65)$ & 0.443 \\
\hline Rural & $19(5.2)$ & $14(3.9)$ & 1.00 & 1.00 & \\
\hline \multicolumn{6}{|l|}{ Extra workload } \\
\hline Yes & 46 & 65 & $0.64(0.13-0.89)$ & $0.88(0.75-1.06)$ & 0.155 \\
\hline No & 127 & 114 & 1.00 & 1.00 & \\
\hline \multicolumn{6}{|l|}{ Mother education } \\
\hline No formal educ. & $69(19.06)$ & $74(20.4)$ & $0.9(0.76,1.01)$ & $0.62(0.37,0.92)^{*}$ & 0.036 \\
\hline Attended formal ed. & $112(30.9)$ & $108(29.8)$ & 1.00 & 1.00 & \\
\hline \multicolumn{6}{|l|}{ Mother occupation } \\
\hline House wife & $75(20.7)$ & $46(12.7)$ & $1.32(1.18,1.51)$ & $1.28(0.92-2.13)$ & 0.365 \\
\hline Paid work & $133(36.7)$ & $108(29.8)$ & 1.00 & 1.00 & \\
\hline \multicolumn{6}{|l|}{ Skip breakfast } \\
\hline No & 173 (47.5) & $126(34.8)$ & $1.9(1.34-3.20)$ & $2.1(1.42-5.76)^{*}$ & 0.026 \\
\hline Yes & $27(7.5)$ & $38(10.5)$ & 1.00 & 1.00 & \\
\hline \multicolumn{6}{|l|}{ Child stunted } \\
\hline Yes & $51(14.1)$ & $58(16.0)$ & $0.61(0.23-0.91)$ & $0.66(0.12-0.93)^{*}$ & 0.042 \\
\hline No & $149(41.2)$ & $104(28.7)$ & 1.00 & 1.00 & \\
\hline \multicolumn{6}{|l|}{ Underweight } \\
\hline No & $124(34.2)$ & 72 (19.9) & 1.00 & 1.00 & \\
\hline Yes & 78 (21.5) & $88(24.3)$ & $0.52(0.27-0.78)$ & $0.57(0.23-0.82)^{*}$ & 0.033 \\
\hline
\end{tabular}

* Statistically significant association 
which could affect brain glucose utilization which in turn results in poor academic achievement.

Skipping breakfast was associated with poor academic performance in the present study. Children who didn't skip their breakfast were 2 times more likely to have good academic score. The longitudinal study conducted among Australian children also revealed that over all academic achievement were higher in breakfast non-skippers than breakfast skippers [19]. A cross sectional study conducted in southern Ethiopia also shown that habit of skipping breakfast affected the cognitive performance of early adolescents [20]. This could be due to deficiency in maintaining adequate levels of glucose throughout the day which contributes to optimizing cognition.

The odd of good academic performance was observed among males than females in the current study (AOR: 2.8 ; 95\% CI 1.79-4.52). Similarly, study conducted in primary schools of rural Malaysia revealed that boys have higher cognitive score than girls but lower in academic tests [8]. On the other hand, a study conducted on predictors of academic performance in Southwest Ethiopia showed that girls had good academic performance than boys [13]. The dissimilarity between these studies might be due to the difference in demography, time of study, and residential area (urban or rural) of the respondents. Participants' mothers' educational status was another factor affecting the academic performance of children. Those children who had no educated mother had poor academic performance than their counterparts (AOR: 0.62; 95\% CI 0.37-0.92). Plenty of studies supports that educational status of parents independently affects the school performance of their children. Studies conducted by Firehiwot et al., Farooq et al., Eshetu et al. and Saimul et al. [13, 21-23] shown that having educated parents have positive association to good academic score of their school children.

\section{Limitations}

The cross sectional design cannot establish causal relationship between variables. The study only assessed whether breakfast was eaten or not and didn't include the quality of the breakfast. Further research is needed to determine whether certain breakfast types are more helpful for cognitive performance. Despite these, we used adequate sample size and mean score of students' average as the cut-off value to say good or poor which could help the findings generalizable to primary school students.

\section{Abbreviations}

BMI: body mass index; EDHS: Ethiopian Demographic and Health Survey; HAZ: height for age Z-score; WAZ: weight for age Z-score; WHO: World Health Organization.

\section{Acknowledgements}

We would like to acknowledge all staffs of Nekemte full cycle primary Schools for their cooperation during data collection, and data collectors, supervisors and study participants.

\section{Authors' contributions}

AT and DS designed and supervised the study and ensured quality of the data and made a substantial contribution to the local implementation of the study, and RT assisted in the analysis and interpretation of the data. RT wrote the manuscript and had the responsibility to submit the manuscript for publication. AT and DS highly participated in revising this paper. All authors read and approved the final manuscript.

\section{Funding}

No funding was received from any organization or individuals to undertake this study.

\section{Availability of data and materials}

All data sets used are available within the manuscript

\section{Ethics approval and consent to participate}

Ethical clearance was obtained from Wollega University's research ethics review committee, and verbal assent was also obtained from each study participants. Permission from Nekemte full cycle primary schools was asked. Parents or guardians of the participating students were informed about the objective, risks and benefit of the study. Confidentiality of data and privacy of the information were also assured. Written and signed informed consent was obtained from the parents or guardians to participate in this study. Students were told on full freedom to participate or not to participate in the study. Privacy of students during anthropometric measurements was kept. In addition, confidentiality of the results was insured by assigning identification number during registration.

\section{Consent for publication}

Not applicable.

\section{Competing interests}

The authors declare that they have no competing interests.

\section{Author details}

${ }^{1}$ Institute of Health Sciences, Wollega University, Nekemte, Ethiopia. ${ }^{2}$ Rift Valley University, Nekemte, Ethiopia.

Received: 30 September 2019 Accepted: 29 October 2019

Published online: 06 November 2019

\section{References}

1. Sarma MS, Wijesinghe DG, Sivananthawerl T. The effects of nutritional status on educational performance of primary school children in the plantation sector in Nuwara Eliya educational zone. Trop Agric Res. 2013:24(3):203-14.

2. UNICEF. Annual results report 2017 education. New York: UNICEF; 2017.

3. Ethiopia Ministry of Education. Program-for-results information document (PID) concept stage. Report No.: PIDC0110495. Addis Ababa; 2017.

4. Haile D, Nigatu D, Gashaw K, Demelash H. Height for age z score and cognitive function are associated with Academic performance among school children aged 8-11 years old. Arch Public Health. 2016;74(1):17.

5. Faught EL, Williams PL, Willows ND, Asbridge M, Veugelers PJ. The association between food insecurity and academic achievement in Canadian school-aged children. Public Health Nutr. 2017;20(15):2778-85.

6. Sinurat RS, Sembiring T, Azlin E, Faranita T, Pratita W. Correlation of nutritional status with academic achievement in adolescents. IOP Conf Series Earth Environ Sci. 2018;125:012226.

7. Kim SY, Sim S, Park B, Kong IG, Kim JH, Choi HG. Dietary habits are associated with school performance in adolescents. Medicine. 2016;95:12.

8. JMt HJ, Mitra AK, Hasmiza H, Pim CD, LOr N, WM'WM, Prcgnmme IN. Effect of gender and nutritional status on academic achievement and cognitive function among primary school children in a rural district in Malaysia. Malays J Nutr. 2011;17(2):189-200. 
9. CDC. Health and academic achievement national center for chronic disease prevention and health promotion. Atlanta: CDC; 2014.

10. Nutrition and Students'Academic Performance. 2014. Available from: https://www.wilder.org/sites/default/files/imports/Cargill_lit_review_114.pdf. Accessed 25 Sept 2019.

11. USAID. Ethiopia: Nutrition Profile. 2018. Available from: https://www.usaid .gov/sites/default/files/documents/1864/Ethiopia-Nutrition-Profile-Mar20 18-508.pdf. Accessed 15 Sept 2019.

12. Wolde T, Belachew T. Chronic undernutrition (stunting) is detrimental to academic performance among primary schools of adolescent children: a randomized cross sectional survey in Southern Ethiopia. BMC Res Notes. 2019;12:142.

13. Abebe F, Geleto A, Sena L, Hailu C. Predictors of academic performance with due focus on undernutrition among students attending primary schools of Hawa Gelan district, Southwest Ethiopia: a school based cross sectional study. BMC Nutr. 2017;3:30.

14. Admasie A, Ali A, Kumie A. Assessment of demographic, health and nutrition related factors to a school performance among school children in Arb-Gebeya Town, Tach-Gaynt Woreda, South Gondar, Ethiopia. Ethiop J Health Dev. 2013;27(2):104-10.

15. Population and Housing Census OF Ethiopia. Administrative report. Central Statistical Authority; 2012.

16. World Health Organization. WHO child growth standards. Geneva: WHO; 2006

17. Mekonnen H, Tadesse T, Kisi T. Malnutrition and its correlates among rural primary school children of Fogera District, Northwest Ethiopia. J Nutr Disord Ther. 2013;2013:S12.
18. Gashu D, Stoecker BJ, Bougma K, Adish A, Haki GD, Marquis GS. Stunting, selenium deficiency and anemia are associated with poor cognitive performance in preschool children from rural Ethiopia. Nutr J. 2016;15:38

19. Smith KJ, Blizzard L, MCNaughton SA, Gall SL, Breslin MC, Wake M, et al. Skipping breakfast among 8-9 year old children is associated with teacher-reported but not objectively measured academic performance 2 years later. BMC Nutr. 2017;3:86.

20. Adole AA, Ware MB. Assessment of breakfast eating habits and its association with cognitive performance of early adolescents (11-13 years) in Shebedino District, Sidama Zone, Southern Ethiopia. J Food Nutr Sci. 2014;2(4):130-7.

21. Farooq MS, Chaudhry AH, Shafiq M, Berhanu G. Factors affecting students' quality of academic performance: a case of secondary school level. J Qual Technol Manag. 2011;7(2):01-14.

22. Eshetu AA. Parental socio-economic status as a determinant factor on academic performance of students in regional examination: case of Dessie town; Ethiopia. Int J Acad Res Educ Rev. 2015;3(9):247-56.

23. Saimul M, Saw A, Islam MA. Prevalence of underweight and effect of nutritional status on academic performance of primary school children in Chapainawabganj District, Bangladesh Malaysian. J Nutr. 2014;20(1):71-81.

\section{Publisher's Note}

Springer Nature remains neutral with regard to jurisdictional claims in published maps and institutional affiliations.
Ready to submit your research? Choose BMC and benefit from:

- fast, convenient online submission

- thorough peer review by experienced researchers in your field

- rapid publication on acceptance

- support for research data, including large and complex data types

- gold Open Access which fosters wider collaboration and increased citations

- maximum visibility for your research: over 100M website views per year

At BMC, research is always in progress.

Learn more biomedcentral.com/submissions 